\title{
Indignation, Appreciation, and the Unity of Moral Experience
}

\author{
Uriah Kriegel \\ Forthcoming in Ethical Theory and Moral Practice \\ (special issue on moral phenomenology)
}

\section{Introduction/Abstract}

Moral experience comes in many flavors. Some philosophers have argued that there is nothing common to the many forms moral experience can take. In this paper, I argue that close attention to the phenomenology of certain key emotions, combined with a clear distinction between essentially and accidentally moral experiences, suggests that there is a group of (essentially) moral experiences which in fact exhibits significant unity.

\section{The Diversity of Moral Experience}

Some of our mental states embody moral commitments, some do not. Thinking that the table is brown and deciding to read this rather than that novel, for instance, have no obvious moral dimension; believing that genocide is wrong and deciding to donate to an anti-corruption charity, in contrast, do. Of our morally committal mental states, some are consciously experienced but many are not. For most of our lives, the belief that genocide is wrong is not consciously entertained; in contrast, a decision to donate to charity is typically taken consciously. For now, let us call the domain of mental states which both embody moral commitment and are consciously experienced 'moral experience' - and the study of this domain 'moral phenomenology.'

Is there anything common to all moral experiences, in virtue of which they are moral experiences? One is forgiven for being antecedently skeptical, and several 
philosophers have developed explicit arguments for a negative answer (Yasenchuk 1997, Gill 2008, Sinnott-Armstrong 2008). In the remainder of this section, I discuss SinnottArmstrong's argument. The discussion will issue in a clear challenge for any unitary account.

Sinnott-Armstrong's argument is in two parts. In the first instance, he claims that moral experiences fall into two separate categories, which he calls moral thinking and moral deciding. Moral thinking is the process whereby we come to form a judgment about a moral matter - to endorse some 'moral belief content' (2008: 87), i.e., the kind of content that might be taken up in a moral belief. Once we have formed such a judgment, however, there is still the matter of deciding to act in accordance with this judgment - to do the right thing. This is a separate and independent form of moral experience, since 'moral judgment can be made without any such decision, and the decision can be made without any conscious moral judgment' (Ibid.). The independence of moral thinking and moral deciding represents for Sinnott-Armstrong a first aspect of disunity in moral experience.

At the same time, in reflecting on what might unite moral thinking and moral deciding, we should consider what might separate each from its nonmoral counterpart. Something distinguishes moral from nonmoral thinking and moral from nonmoral deciding. And whatever that is, it might very well represent a measure of similarity between moral thinking and moral deciding. Suppose, for the sake of illustration, that moral thinking is distinguished from nonmoral thinking by the fact that it is thinking about right and wrong, and that moral deciding is distinguished from nonmoral deciding by the fact that it is deciding about right and wrong. Then although moral thinking and moral deciding are clearly different, insofar as thinking and deciding are, they are also importantly similar, insofar as both concern right and wrong. To be clear, this proposal is intended merely for illustrative purposes and I do not take it to be ultimately plausible. Thinking about which is the right hand to hold the fork, or which would be the right shot to take in a basketball game, is not moral thinking. The point is just that something distinguishes moral from nonmoral thinking, and something also distinguishes moral from nonmoral deciding, and it would be no surprise if it turned out to be the same 'something.'

In any event, the more central part of Sinnott-Armstrong's case against the unity of moral experience pertains to the considerable phenomenal disunity he finds even within the circumscribed domain of 'moral thinking.' Sinnott-Armstrong tentatively adopts a theory of morality popular from the social psychology and anthropology of the day, according to which societies everywhere are governed by four kinds of moral rule, violation of each of which is met with a distinctive emotional reaction (Shweder et al. 1997, Haidt and Joseph 2004). The four moral spheres are: the morality of autonomy (forbidding, e.g., the gratuitous harming of another), the morality of community (demanding, e.g., 
respect and deference to parents), the morality of purity (banning, e.g., incestual relations among consenting adults), and the morality of reciprocity (requiring, e.g., that we keep our promises). Violations of autonomy, the theory claims, are met with anger, violations of community with contempt, of purity with disgust, and of reciprocity with resentment.

Although Sinnott-Armstrong endorses this framework only very partially, he draws from it the following lesson:

Details aside, the main point is that various areas of morality feel very different. Anger does not feel anything like disgust, contempt, and distrust [or resentment]. Just consider what it is like to ... be the victim of a violent robbery. Now imagine eating human flesh or witnessing adult consensual sex. Next consider spitting on your father's grave... When I introspect on this variety of cases, it is hard for me to find anything interesting that is common or peculiar to these moral experiences. (2008: 89)

Here is the core of Sinnott-Armstrong's case against the unity of moral experience: introspective reflection on the variety of our characteristic emotional reactions to moral states of affairs reveals no evident similarity but on the contrary a wide phenomenal diversity.

In response, the first thing to point out is this: although Sinnott-Armstrong is surely right that 'Anger does not feel anything like disgust, contempt, [etc.],' it is not clear that anger is more phenomenally different from disgust and contempt than visual experience is from olfactory and tactile experience. Seeing a tree does not feel anything like smelling coffee or touching velvet. Yet few would deny that there is some phenomenal unity to perceptual experience, which distinguishes it from (e.g.) conscious thought or emotion. It is just that the phenomenal similarity among perceptual experiences - the phenomenal feature shared by all and only perceptual experiences - is likely extremely subtle, more elusive than, say, phenomenal redness or phenomenal bitterness. ${ }^{1}$

By the same token, now, there may well be a subtle similarity between the experiences of anger, contempt, and disgust that constitutes an important measure of phenomenal unity. Nothing Sinnott-Armstrong says rules out this kind of subtle phenomenal commonality. The considerable phenomenal dissimilarity across our experiential reactions to moral issues is perfectly compatible with the existence of a delicate thread running through them.

At the same time, we can read Sinnott-Armstrong as issuing a challenge to the proponent of unity: show us the subtle phenomenal feature that might unite the domain of moral experience. The purpose of this paper is to try and meet this challenge. In the next section, I distinguish between a broad and a narrow notion of moral experience. After that, I will argue for a phenomenal commonality among moral experiences in the narrow sense. 
Before starting, a word on the expression 'phenomenal commonality.' Some people hear 'phenomenal' as meaning something purely sensory, so that for moral experiences to have a phenomenal commonality their subjects would have to share a specific sensation. My notion of the phenomenal is much wider, however, and encompasses everything the subject experiences. It is possible to hold, of course, that only sensory elements can be experienced, but following many others, I deny this (Kriegel 2015).

\section{What is a Moral Experience?}

Last week I cleared a morning to help a friend move into a new apartment. After three hours of moving, and with lunchtime looming, she mentioned that someone on the other side of town had offered her a sofa, and asked whether I could spare my afternoon to haul it over. Of course in some sense I could, but there were also other things I had planned to do in the afternoon. There was an important soccer game I wanted to watch with my son, for instance. I lingered there silent for a long three seconds, thinking to myself: 'I really don't feel like it! I was looking forward to catching that game. That said, she's new in town and doesn't know anybody here - I don't really see how she could do it if I said I didn't have the time. I guess she could live without a sofa - much of humanity manages to be happy without a sofa. Anyway... I guess I know what's the right thing to do here - I just don't feel like doing it!' Importantly, I did not feel any social discomfort about saying no. But somehow, I ultimately came up with the necessary quantity of moral effort and said 'let's do it.' That evening, getting ready to go to sleep, I felt a tinge of pride for coming up with the requisite moral effort (mindful, of course, that greater acts of self-sacrifice have been known to grace this earth).

This fleeting emotional episode, that nightly tinge of pride, is clearly in some sense an episode of moral emotion: I took pride in benefiting someone at my own expense, and doing so just because it was the morally right thing to do. The object of this emotional episode was a moral act, and in this sense it is surely a moral emotion. At the same time, it is noteworthy that there is nothing about pride as such that restricts it to the moral realm. Most of what I am proud of is entirely amoral, or at least is so experienced in my pride. Of the many philosophy papers I have written, there is a handful of which I am proud. More precisely, I am proud of having produced them. But there was no moral effort involved in producing them. When I was writing those papers, there was nothing I felt like doing more than writing them. No sacrifice, no exercise of moral distinction, was in any way involved. There is perhaps some value involved, but it need not be moral value. Pride 'tells a story,' says Antti Kauppinen (2017: 169), and 'the shape of the story, roughly, is that there was something challenging that needed to be done to promote or protect some good, and I did it.' With my handful of papers, I would like to think I promoted some philosophical or 
intellectual good. But I am under no illusion that any moral good has been promoted by my paper on metametaphysics.

There is a sense, then, in which there is nothing inherently moral about pride as such. There is nothing in the nature of pride, as the type of mental state it is, that ties it necessarily or constitutively to morality. In this respect, it is somewhat accidental to my pride in helping my friend move the sofa that it is a moral emotion: it concerns a moral occurrence, certainly, but it is not the kind of emotional episode it is impossible to undergo outside the moral context. Some occurrences of pride encode a certain moral evaluation, but many do not. Pride is not, we might say, an essentially moral emotion.

Might one argue that there are simply two kinds of pride, moral pride and nonmoral pride, and the former is essentially moral? One could, of course, just as one could argue that there are two kinds of visual perception, perception of blue and perception of nonblue. And in one sense it is true that there are these two kinds of visual perception. But the distinction between blue and nonblue seems to pertain to the kinds of object visual perception could take, and not to the nature of visual perception itself as a type of mental state. To be clear, I do not think it is straightforward just what underlies the distinction between differences in psychological nature and differences in intentional object; far from it. But I record that we have a robust intuition that the distinction between visual and auditory perception is a difference in the nature of the mental state types whereas the difference between visual perception of blue and visual perception of nonblue falls short of that and pertains only to the objects different token perceptual states happen to take. And I now add the following substantive claim: the proposed distinction between moral pride and nonmoral pride seems more like the distinction between visual perception of blue versus nonblue than like the distinction between visual versus auditory perception. Following Kauppinen, I claim that it is in the nature of pride, as a mental state type, to present its object as a value-producing effortful act; but whether the good in question is a moral good or some other kind of good is a matter of the state's intentional object.

Guilt offers an instructive contrast here. Where my moral pride said, so to speak, 'I benefitted someone,' guilt tends to say 'I harmed someone.' But there appears to be an important difference: guilt cannot but take as its object a moral harm. There is no other kind of harm guilt can be fittingly directed at. Compare Bobbie Sue and Sue Ellen. Bobbie Sue, a shift manager at Burger King, is tasked with firing one of her two underlings. One of them is a cool young dude Bobbie Sue enjoys chatting with; the other is a middle-aged guy who spends his time complaining about his alimony and child support debts. Bobbie Sue fires the latter, but later that night is visited by pangs of guilt: in truth, he needs the income much more, and his age and skill sets make his position on the labor market much more precarious. Bobbie Sue's guilt is rational and fitting; she should feel guilty. Compare now 
Sue Ellen, a shift manager rather at McDonald's, who faces the same task, but must choose between two underlings equally cool and equally necessitous. She deliberates at length, finds no reason to fire one rather than the other, flips a coin, and fires A rather than B. Even if it is perfectly rational and fitting for Sue Ellen to feel a certain type of regret later that night, guilt proper would be quite out of place. She has not wronged A, although she has certainly harmed him.

My point is that, whatever other asymmetries there might be between guilt and pride, one asymmetry is that guilt is an essentially moral emotion, whereas pride is not. Both guilt and pride encode (self-)evaluation, but guilt's evaluation is always moral evaluation, whereas pride's is sometimes moral and sometimes not. It is in the very nature of guilt, as the type of mental state it is, to morally evaluate its object; not so pride.

There is an important objection we should consider. Why could one not say that just as there is moral pride and nonmoral pride, there is also moral regret and nonmoral regret, and English simply happens to be generous enough to provide us with a dedicated word for moral regret - namely, 'guilt' - but not for moral pride? According to this objection, the pride/guilt asymmetry is not really an asymmetry in the experiential reality of our psychological repertoire, but an asymmetry in the natural-language vocabulary we have for describing it. A deeper objection may lurk here, of course: that there is no principled distinction between differences in nature and differences in object, and by implication between essentially moral experience and accidentally moral experience.

Perhaps the pride/guilt asymmetry will turn out to be more about language than about emotional experience (though I doubt it, on phenomenological grounds). But it is surely implausible that there are no differences between emotional experiences that are not differences in object but go rather to the very nature of certain mental state types. The familiar distinction between content and attitude certainly suggests this. A belief that $p$ and a desire that $p$ have the same intentional object, but have it, so to speak, in different ways: the former is directed at $p$ belief-wise, the latter desire-wise. What is meant here by 'beliefwise' and 'desire-wise'? Various accounts have been offered, in terms of 'functional role,' 'direction of fit,' architectural 'boxes,' and various other notions. But at the most fundamental level, it is clear that $p$ is represented in a different way by the belief and by the desire. There is a classical tradition, going back at least to Aquinas, according to which belief represents its object sub specie veri - under the guise of the true - while desire represents its object sub specie boni - under the guise of the good (Tenenbaum 2009). One may contest various aspects of this, notably the idea that desires always represent their objects as good (Velleman 1992). Still, there is surely some distinctive guise under which desire represents its objects that differs from belief's proprietary guise. That is, there are some guises $\mathrm{B}$ and $\mathrm{D}$, such that (i) belief represents its object under the guise of the $\mathrm{B}$, 
whereas desire represents its object under the guise of the D, and (ii) B and D really and fundamentally pertain to different ways of representing the object, not to the object itself. It is not as though belief and desire relate in the same way to different objects, belief to the proposition $<p$ is $\mathrm{B}>$ (e.g., $<p$ is true $>$ ) and desire to $<p$ is $\mathrm{D}>$ (e.g., $<p$ is good $>$ ). No, they relate differently to the same object: the belief represents-as-B (perhaps: represents-astrue) the proposition $\langle p\rangle$, while desire represents-as-D (perhaps: represents-as-good) the same proposition. This is irreducibly a difference not in object, but in the manner of representing that object, a manner of representation that is proprietary to belief and to desire respectively and makes them the mental state types that they are.

If this is right, then the distinction between accidentally and essentially moral experience comes down to the distinction between experiences with moral content (i.e., experiences whose intentional object is moral) and experiences with moral attitude (i.e., experiences that are moral by their very nature as the types of mental state they are). The latter are experiences the occurrence of which necessarily encodes moral evaluation, and does so in virtue of their very nature as the mental state types they are.

To give more texture to this notion of essentially moral experience, in the next section I discuss two experiences that I claim to be examples. I will argue that when we get clear on what makes them essentially moral experiences, we also come to see that there is an evident phenomenal commonality between them. Later I will argue that we have every reason to suppose there is some phenomenal commonality across all essentially moral experiences.

\section{Two Essentially Moral Experiences}

Imagine, if you can, that you receive a rejection email from a journal. If you are anything like me, your first reaction will feature prominently a coalition of unpleasant feelings: pain and disappointment, certainly, with a sharper or milder sinking of the heart, perhaps tinted with a subtle sort of sheepishness or self-doubt, an inward shrinking that says 'the truth is I'm just not good enough.' But imagine you then go on to read the basis for this rejection: a single report from a lazy referee who completely misunderstood even the most basic elements of the paper and in truth did not really engage with it. Again if you are like me, your initial pain is likely to morph into something more in the nature of anger: the inward shrinking gives way to a more aggressive, outward-flowing feeling. Your anger experience is at least as unpleasant as pain, disappointment, and self-doubt, but its form of displeasure also incorporates an element of grievance: it blames - the referee, the editors, someone.

This seems an essential difference between painful and angry feelings. The kind of emotional transition just described surely varies in detail across persons and occasions. 
But a core feature is that while pain involves centrally the sense that something bad happened to me, anger goes beyond it in involving also the sense that someone is responsible for this bad thing happening to me (which is not to say, of course, that anything like this need be explicitly articulated in the mind of the pained or angry!). This is why anger blames: it assigns responsibility for something bad. My suggestion is that this is an essential difference between pain and anger: pain casts its object as bad for me, anger casts its object as blameworthy for something bad for me. ${ }^{2}$

This difference seems moreover to go to the essence of pain and anger. A feeling would not be a painful feeling if it involved no sense of anything bad happening to one, and a feeling would not be an angry feeling if it involved no sense of blame. To that extent, the element of blaming that distinguishes anger from pain must belong in the very attitude of anger, not merely in its content. It is not a matter of the intentional object of anger, but a matter of the very manner in which anger intentionally relates to its object, the guise under which it represents whatever it represents. Anger cannot but blame. We might say that feeling anger toward the referee consists in undergoing an experience that represents-asblameworthy the referee; the referee is what the experience represents (the experience's object), representing-as-blameworthy is how the experience represents (the experience's attitude or guise). By the same token, feeling pained by a journal rejection involves representing-as-bad-for-me a journal rejection; the journal rejection is what the experience represents (object), representing-as-bad-for-me is how the experience represents (guise). Thus the difference between pain and anger reflects, I would insist, the difference between the presence and absence of emotionally felt attribution of responsibility ('emotionally felt' as opposed to 'disinterestedly judged').

Pain and anger are negative emotions, but a parallel difference can be found, in the sphere of positive emotions, between pleasure and gratitude. Pleasure refers only to a benefit ('something good happened to me'), gratitude also to a benefactor, that is, to someone responsible for this benefit - someone who is therefore praiseworthy. Junior is pleased to eat ice cream, but is grateful to grandma for buying him ice cream. His pleasure represents-as-good-for-him eating the ice cream; his gratitude represents-as-praiseworthy grandma. Where anger blames, gratitude praises.

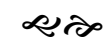

I now want to explore another kind of emotional transition. Suppose you come off an airplane and get into a taxi, only to realize to your horror that you had lost your wallet, probably on the plane. In the grip of anxiety, you rush to the airport Lost \& Found, where a woman takes down your information, tells you that these cases take typically an hour or two to resolve, and asks you to return approximately an hour later. After forty minutes of anxious meandering, you return to the office, where she hands you your wallet - 
everything in it - with a kind smile on her face. 'It was indeed on the airplane,' she tells you. You cannot help but feel a gush of tremendous gratitude to this stranger, who after all was just doing her job. As you leave the office and wait for the elevator, though, a guy from the Lost \& Found office tells you that she actually went through quite an ordeal to get your wallet. Apparently she personally went to the gate, insisted somewhat tensely with the crew that the airplane must be searched before it takes off again, and eventually went in herself and retrieved your wallet from the side of your seat. She did all this, you are told, because she saw how distraught you were. As you hear this, a new feeling dawns on you. It is not only an intensification of your gratitude. There is also a quality of appreciation for the person herself, independently of how she relates to you. She did not have to do all that, you feel, but she is just a good person. Her actions did not just benefit you, but exhibited or embodied a measure of moral excellence. This new feeling, this appreciation of the person, does not bend toward the person the way gratitude does, but on the contrary moves back from her, as it were to take a fuller measure of the objective goodness of the person or her act. What this new feeling of appreciation 'says' is not just that something good happened to you, but that something good happened, or exists. (The name 'appreciation' is suboptimal, but bests all alternatives - more on this at the end of this section.)

The main contrast I want to draw here is between gratitude and (this kind of) appreciation: although both present their object as responsible for some good, gratitude presents its object as responsible for something good-for-me, whereas appreciation presents its object as responsible for something good-simpliciter. This explains the following striking asymmetry between gratitude and (the relevant kind of) appreciation: while you can feel grateful only for an act of beneficence in which you yourself are the beneficiary, the relevant kind of appreciation is something you can feel toward an act of beneficence between two third parties. If you see someone go out of his way to help a blind stranger cross the street, then pending some projective identification on your part, you cannot quite feel grateful for this act, but you can certainly appreciate it in the relevant sense. Where gratitude says - so to speak - 'someone benefited me,' this kind of appreciation says 'someone benefited someone.' It detaches itself from one's own involvement in the situation and presents an act of beneficence in an 'objective' light. ${ }^{3}$

It is crucial to notice that the transition from gratitude to appreciation involves a difference in kind, not just in degree. We can imagine a sorites-like series of cases in each of which your benefactor is doing a little bit more for you, and such a series suggests differences in degree rather than kinds. But the series we are thereby envisaging pertains only to the intensification of gratitude. In the experiential life of concrete subjects, in addition to degree of gratitude intensity, there would also be a breaking-point in which gratitude would transform into, or would make room alongside it for, the categorically different (loftier-feeling, more removed, etc.) feeling I call appreciation. 
My phenomenological hypothesis, if you will, is that when you move from feeling gratitude to feeling appreciation toward your Lost \& Found helper, you are moving from experiencing her as responsible for something good for you to experiencing her as responsible for something 'objectively' or 'impersonally' good. Because you too are a 'someone,' it is possible for you to experience her help not only as an instance of someone benefiting you, but also as an instance of someone benefiting someone. You happen to be the accidental value of the (second) variable 'someone.' But this is not what appreciation appreciates, so to speak, and in this it differs essentially from gratitude. Both your gratitude and your appreciation evaluate the wallet help positively, but what gratitude values is tied up with the fact that you yourself were benefited; whereas what the appreciation values is the fact that someone was benefited. The appreciation takes distance from the act of beneficence and considers it in an objective light, and the warmth you consequently feel toward the Lost \& Found lady has a newer, somehow 'nobler' quality than sheer gratitude for having been benefitted. Such gratitude can be felt toward a slimy car salesman who proves willing to cut some shoddy corners to save you a cool grand; but the kind of appreciation I have in mind cannot take such a man as its object.

I want to suggest that it is in this kind of transition from felt gratitude to felt appreciation that we enter the realm of the essentially moral emotions. From the perspective of your gratitude, the Lost \& Found helper is responsible for a prudential good; from the perspective of your appreciation, she is responsible for a moral good. This is why it is possible for you to feel grateful to the slimy salesman (whether or not you endorse this feeling!) but impossible for you to appreciate him. We might put this is by saying that the essential difference between gratitude and appreciation is that the experience of gratitude toward $x$ represents-as-prudentially-praiseworthy $x$, whereas the experience of appreciation toward $x$ represents-as-morally-praiseworthy $x$. This is a difference in the natures of these mental state types; to that extent, the relevant kind of appreciation is by its nature a moral emotion in a way gratitude is not.

To be clear, the locution 'represents-as-morally-praiseworthy' is used here as a mere label: it labels the distinctive phenomenology that comes into sharp relief when we consider the experiential transition from gratitude into appreciation. Of course, in choosing the specific words I have used for that label, I am winking at a certain conceptual articulation of the relevant phenomenology. But this conceptual articulation is not what explains in my account the difference between a moral emotion such appreciation and a non-moral emotion such as gratitude; if it did, it would be a somewhat circular explanation, since it invokes the concept of the moral. What does the explaining is rather the phenomenal contrast between the "before" (gratitude) and "after" (appreciation) of the relevant experiential transition. This contrast is supposed in the first instance to focus the mind on a distinctive phenomenal character that seems to capture elements of the 
characteristically moral. The labels, with their overtly moral terms, are then applied to help us keep track of the different attitudes and their interrelations.

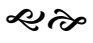

Here too, there is a counterpart in the domain of negative emotions. Suppose you receive a rejection based on a referee report which is not incompetent but somehow dismissive and vaguely malicious. Months later, you learn from an indiscreet mutual friend who the referee was, and learn also that the referee knew you were the author. From interactions with her at various conferences, you have long suspected that she resented you, because of what you can only surmise is that job you got at her expense ten years ago. Your anger about that rejection will likely acquire a new quality - a quality we might call 'indignation' whereby you take a step back and see in a new, more objective light that rejection. It is now experienced as something bad simpliciter, not just bad for you. More precisely, I propose, while your original anger at the rejection involved experiencing the referee as responsible for something prudentially bad, your indignation involves experiencing the referee as responsible for something morally bad. I further propose that this amounts to a difference in representational attitude rather than content: anger represents-as-prudentiallyblameworthy whatever it does, whereas indignation represents-as-morally-blameworthy. Accordingly, indignation in this sense is something you can feel toward an instance of harming between third parties, whereas with anger this is only possible through a kind of projective identification with the harmed party. In the metaphorical terms used above, while anger says 'someone harmed me,' indignation says 'someone harmed someone.'4 Here too, of course, indignation can involve oneself, since one is always a 'someone' and can be morally and not only prudentially harmed (cf. Bommarito 2017: 18). Nonetheless, true indignation is insensitive to the fact that the morally harmed person is oneself; when it seems thus sensitive, it is better thought of as an admixture of anger and indignation (a commonplace cocktail!). It is thus crucial to the difference between anger and indignation that the latter involves a detachment of one's felt evaluation from the specificity of one's own involvement in the situation, with the result that its evaluation is experienced as objective and impersonal in a way anger's is not.

Here too, then, we can say that indignation is an essentially moral emotion whereas anger is not. In that respect, indignation is to appreciation what anger is to gratitude. (To be clear, I am not claiming that the detached character of indignation and appreciation is what makes them moral emotions. Rather, I take it to be a diagnostic symptom of their status as moral emotions.)

The distinctively moral character of indignation explains why, after stubbing one's toe, it is only human, if somewhat silly, to get angry at the table, but totally incongruent to feel indignant about the whole thing; why failure to feel indignation when presented with 
the facts about some moral tragedy (the 'trail of tears,' say) is suggestive of a moral shortcoming in a way failure to feel angry is not (cf. Drummond 2017: 22); and why the fantasies of revenge - including violent, morally pyrrhic revenge - so characteristic of anger are absent in true indignation.

A similar claim of distinctive moral character in indignation is made by Peter Strawson (1962) in his discussion of the contrast between indignation and resentment. Like anger, resentment casts its object as responsible for something bad for one - it, too, blames. But where anger's blame is aggressive and engaging, resentment's has a more withdrawn, bitter quality to it. The resentful has resigned herself to the relevant evil, the angry nurses visions of restored justice through retribution. Despite these differences, both attribute to their object responsibility for a prudential evil - for harm to one's interests. Indignation is in contrast unmoored from the narrow perspective of self-interest and thereby acquires its moral dimension. Strawson (1962: 15) writes:

[0]ne who experiences the vicarious analogue of resentment is said to be indignant or disapproving, or morally indignant or disapproving. What we have here is, as it were, resentment on behalf of another, where one's own interest and dignity are not involved; and it is this impersonal or vicarious character of the attitude, added to its others, which entitle it to the qualification 'moral'.

Some commentators have wondered why Strawson should treat the 'vicariousness' of an attitude as a mark of its moral character (e.g., Mason 2003: 243). But our parallel phenomenological contrast between gratitude and appreciation makes that clear. The vicariousness of appreciation and indignation is really not what matters here, since both can be experienced toward acts directed at oneself. Rather, what matters is that in such experiences one's own involvement in the situation is accidental, and it is the intrinsic profiles of act and actor that are evaluated, not their effect on one's own interests. ${ }^{5}$

In other words, indignation and appreciation bear an important phenomenal resemblance in the dimension of felt objectivity (or 'impersonality') they share, the independence of their concern from the pertinence of one's involvement. This is central to the status of indignation and appreciation as genuinely moral emotions. (Rationalists have tended to think that the objectivity of morality is something we need to call upon reason to capture; I think the present phenomenological analysis shows that this discrimination exists already in our emotional experience.)

Here we can see a meaningful measure of phenomenal unity across distinct moral emotions: insofar as the essential characteristic of appreciation is representing-as-morallypraiseworthy, and that of indignation is representing-as-morally-blameworthy, both represent-as-morally-responsible (since moral blameworthiness and praiseworthiness are 
two species of moral responsibility). Accordingly, indignation and appreciation are two species of a single genus - moral emotion - somewhat as visual and olfactory experiences are two species of a single genus - perceptual experience.

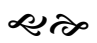

I want to free the above discussion from the shackles of words. Doubtless one could, with no undue infelicity, use the word 'anger' to denote some instances of the kind of feeling I called indignation, or the word 'indignation' to denote some instances of the feeling I called anger. And certainly the word 'appreciation' can be used for any number of mental states other than the essentially moral feeling I have attempted to isolate here. Language is messy, and language use messier yet. But the underlying phenomenal reality may be far more orderly. It may be systematically structured, for instance, by a nested web of genus-species and determinable-determinate relationships, albeit ones no easier to discern in the phenomenal than, say, the biological realm (cf. Dupré 1981). It is not my goal here to make a case for the general idea that phenomenal reality is more disciplined than phenomenological language. What I want to stress is only that the above claims are claims about certain emotional experiences, about their distinctive characters and their essential similarities and dissimilarities; they are not claims about emotion concepts, much less about emotion words. It is, of course, impossible to talk about emotions without using emotion words, and this opens the above discussion to objections which are not really pertinent to it - objections of the form 'Here is a case where Joe Sixpack describes a feeling as indignation that is not specifically moral.' I have no desire to forbid Joe Sixpack his usage of the word, but would insist that the feeling he therewith picks out is not the one of which I speak.

Importantly, this does not render my thesis trivial, since I am not pegging my use of 'indignation' to whatever feeling would conform to my thesis. My approach has been rather to zoom in on specific kinds of emotional experience through consideration of certain experiential transitions, where a certain new phenomenal element comes into introspective relief and is established to pertain distinctly to the experiences one transitions into. This is, in a way, a variant of the 'phenomenal contrast method' commonly used in phenomenological discussions (Siegel 2007). In standard applications of the method, we simultaneously juxtapose two phenomenal states in something like simulative imagination; in the present variant, we contemplate a phenomenal process and try to focus the mind on the phenomenal difference between the beginning and end states of the process. Using this method, I have attempted in this section to isolate two essentially moral emotions and show the phenomenal unity they exhibit. What English words it is most natural to use to pick out these two emotions is the least important aspect of the discussion. 


\section{The Phenomenal Unity of Moral Experience}

In the terms I introduced in $\S 2$, indignation and appreciation are moral experiences in the narrow sense of being essentially morally experiences: it is in their nature, as the mental state types they are, to morally evaluate. Moral evaluation is built into their very attitude; it does not merely feature in the contents of some of their tokens. We have also seen that there is an experiential commonality between these two essentially moral experiences: both represent-as-morally-responsible their objects. But is there an experiential commonality across all essentially moral experiences?

In addressing this question, we face a certain methodological embarrassment. When we ask whether there is a commonality among all dogs, say, we have a pre-theoretic list of all the recognized kinds of dog, and our question is just whether there is a commonality among all those things. But there is no pre-theoretically recognized catalog of moral experiences. Folk psychology employs various mental categories, but the category of moral experience is not among them. The status of any conscious experience as a moral experience is thus contestable and a matter for philosophical or psychological theorizing. When philosophers write papers with such titles as 'Love as a Moral Emotion' (Velleman 1999) or 'Respect as a Moral Emotion' (Drummond 2006), they take themselves to make interesting claims about the nature of specific mental state types, namely, that they are moral in character; they do not take themselves to describe mental states antecedently recognized to be moral in character.

Since there is no canonical list of moral experiences, the question of whether there is an experiential commonality among all moral experiences will mean different things to different people, depending on what their independent commitments are about the extension of moral experience. Naturally, the more liberal and inclusive one's notion of moral experience, the more unlikely such an experiential commonality becomes, and conversely, the more restrictive and exclusive one's list of moral experiences, the more likely a commonality becomes. But without an agreed-upon list of items, there can be no unified project of figuring out what commonality if any there exists within the list.

Now, in §2 I isolated a relatively restrictive notion of moral experience: the 'essentially moral experiences' which cannot but morally evaluate, because it is in their nature, as the mental state types they are, to morally evaluate. I have further suggested that these are the experiences that employ morally evaluative attitudes, as we may expect given that a mental state's attitude is what makes it the mental state type it is. I noted that pride and regret, for instance, can morally evaluate, insofar as they can carry morally evaluative contents, but it is nonetheless not in their (attitudinal) nature to morally evaluate, which is 
why nonmoral pride (e.g., pride in writing a passable article) and nonmoral regret (e.g., for having to fire someone) are perfectly possible.

It might be suggested, then, that we proceed in the following two steps. We start by identifying all the experiential states which are essentially moral in this sense. We do so simply by trying to conceive of token experiences that belong to the same mental state type but involve no moral evaluation (such as the token pride and regret just cited). If we cannot conceive of such token experiences, this would constitute strong prima facie evidence that the relevant experience type is essentially moral. By reiterating this procedure for various experience types, we produce a list of putative essentially moral experiences. Once we have this list, we can seek an experiential commonality across the items thereon. If we find one, we conclude, however tentatively, that the realm of moral experience is phenomenally unified; if we do not, we conclude the opposite. This procedure would seem to give us a methodology with which to approach the question we are interested in.

There is, however, a different methodological embarrassment involved in this procedure. It is that the criterion used to decide which items to admit on our list basically guarantees that there be a commonality among the admitted items. Consider: in order to qualify as an essentially moral experience, an experience must employ a morally evaluative attitude. If it does not feature such an attitude, it does not make it to our list, and if it does feature one, it does make it. But now whatever the items we end up with on our list, when we consider whether these items have anything in common, the answer is trivially yes: they are all, quite obviously, experiences that employ a morally evaluative attitude. We know two such experiences - those we have called indignation and appreciation. The former employs a morally evaluative attitude insofar as it attitudinally evaluates for moral blameworthiness, the latter employs a morally evaluative attitude insofar as it attitudinally evaluates for moral praiseworthiness. Plausibly, there are other essentially moral experiences in our psychological repertoire. But whatever these are, by definition they would employ attitudes which morally evaluate their object. It is thus guaranteed that the answer to 'Is there anything in common to all essentially moral experiences?' is positive: they all employ morally evaluative attitudes.

This 'methodological embarrassment' comes down to this. If we want to consider whether there is a commonality among all $x \mathrm{~s}$, we must have either (a) a pretheoretically recognized list of $x \mathrm{~s}$, such that we can consider whether they have anything in common, or (b) a criterion for $x$-hood that allows us to draw our own list. In the case of moral experiences, however, we do not have (a), while (b) produces a positive answer automatically and trivially.

I present this methodological embarrassment only half-seriously, however. I think things are in reality not so bad. What the above line of thought shows, I think, is that there 
is no satisfying way to establish a universal of the form 'All moral experiences are phenomenally F.' However, the considerations raised in §§2-3 do offer strong evidence for the following interesting existential: There is a class of experiences E, such that all Es morally evaluate as part of their attitude, hence as part of what makes them the mental state types they are. This existential establishes that there is an important class of experiential states, specially deserving of the label 'moral experiences,' that have something significant in common. For anyone interested in the unity of moral experience, accepting or rejecting this existential would surely feel like meaningful progress.

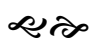

As noted, we have pointed out only two instances substantiating the existential indignation and appreciation. In $\S 1$, I also floated the likelihood that guilt is another such instance, another essentially moral experience. ${ }^{6}$ Let me close by pointing in the direction of what strike me as two other essentially moral emotions, so to speak to round up an initial list of experiences employing morally evaluative attitudes.

The first experience is a specific kind of respect, a kind that corresponds roughly to Kantian respect for persons - what Stephen Darwall (1977) called 'recognition-respect' and distinguished from 'appraisal-respect.' Appraisal-respect is directed at individuals in virtue of their accomplishments, virtues, skills, or other distinctive merits; it is not an essentially moral emotion, since the respect-grounding merits need not be moral merits: it is possible to respect in this way someone for running really fast. Recognition-respect is in contrast an undiscriminating kind of respect directed at any person purely because he or she is a person. The phenomenology of recognition-respect is extremely rich and subtle (Kriegel and Timmons forthcoming), but a core feature is experiencing another as possessing dignity equal to one's own, an intrinsic and irreplaceable worth that demands treatment as an end rather than mere means. This very much seems like an essentially moral emotion. When we recognition-respect a person, we represent-as-having-dignity that person. Representing-as-having-dignity is a manner of moral evaluation: it presents its object as endowed with special worth or value that creates moral demands on us.

Insofar as the counterpart of respect in the sphere of negative emotions is something like contempt, we may also identify a variety of contempt whose very nature is to deny someone dignity. It is doubtless possible to feel 'appraisal-contempt' for someone in virtue of their special failings or demerits (see, e.g., Mason 2003: 250), a contempt we would only rid ourselves of when we feel these failings or demerits have been overcome or compensated for. But in the kind of elemental contempt I have in mind, we experience a violent annihilation of the other's very personhood, his or her fundamental dignity and worth. This, too, would clearly be an essentially moral experience. Insofar as recognitionrespect employs the attitude of representing-as-having-dignity its object or content, the 
corresponding type of contempt employs something like the attitude of representing-aslacking-dignity.

Our existential is becoming ever more interesting. It now states that there is a class of experiences, featuring (perhaps inter alia) certain specific types of indignation, appreciation, respect, contempt, and guilt, which have an important commonality insofar as they all employ morally evaluative attitudes. It is this existential that I am offering as the upshot of the present investigation. The investigation is however incomplete: it is a live question what the full list of 'essentially moral experiences' is. Other items - perhaps certain types of care and/or sympathy - may well need to be added to obtain the full list. One suspicion we can air already on the basis of the discussion here is that all essentially moral experiences are emotions. We may well have moral beliefs and moral desires, and these may well be experienced sometimes, but belief and desire do not by their nature evaluate morally, so moral belief and desire are not essentially moral experiences. When we contemplate our entire psychological repertoire, and consider which experienced mental state types morally evaluate in virtue of their proprietary attitude, I suspect we will find that only emotional states do. This would give emotion a kind of pride of place in our moral life. $^{7}$

\section{References}

- Bommarito, N. 2017. 'Virtuous and Vicious Anger.' Journal of Ethics and Social Philosophy 11 (3): $1-27$.

- Darwall, S.L. 1977. 'Two Kinds of Respect.' Ethics 88: 36-49.

- Drummond, J.J. 2006. 'Respect as a Moral Emotion: A Phenomenological Approach.' Husserl Studies 22: 1-27.

- Drummond, J.J. 2017. 'Anger and Indignation.' In J.J. Drummond and S. Rinofner-Kreidl (eds.), Emotional Experiences: Ethical and Social Significance. London and New York: Rowman \& Littlefield.

- Dupré, J. 1981. 'Natural Kinds and Biological Taxa.' Philosophical Review 90: 66-90.

- Gill, M.B. 2008. 'Variability and Moral Phenomenology.' Phenomenology and the Cognitive Sciences 7: 99-113.

- Haidt, J. and C. Joseph 2004. 'Intuitive ethics: How innately prepared intuitions generate culturally variable virtues.' Daedalus, Fall 2004: 55-66. 
- Kauppinen, A. 2017. 'Pride, Achievement, and Purpose.' In J.A. Carter and E.C. Gordon (eds.), The Moral Psychology of Pride. London: Rowman and Littlefield.

- Kriegel, U. 2015. The Varieties of Consciousness. Oxford and New York: Oxford University Press.

- Kriegel, U. 2019. 'The Perception/Cognition Divide: One More Time, with Feelings.' In C. Limbeck-Lilienau and F. Stadler (eds.), The Philosophy of Perception and Observation. Berlin and Boston: De Gruyter.

- Kriegel, U. and M.C. Timmons forthcoming. 'The Phenomenology of Kantian Respect for Persons.' In R. Dean and O. Sensen (eds.), Respect. Oxford: Oxford University Press.

- Mason, M. 2003. 'Contempt as a Moral Attitude.' Ethics 113: 234-272.

- Manela, T. 2016. 'Gratitude and Appreciation.' American Philosophical Quarterly 53: 281-294.

- Shweder, R.A., N.C. Much, M.M. Mahapatra, and L. Park 1997. "The "big three" of morality (autonomy, community, and divinity) and the "big three" explanations of suffering.' In A.M. Brandt and P. Rozin (eds.), Morality and Health. New York: Routledge.

- Siegel, S. 2007. 'How Can We Discover the Contents of Experience?' Southern Journal of Philosophy (supplement) 45: 127-142.

- Sinnott-Armstrong, W. 2008. 'Is Moral Phenomenology Unified?' Phenomenology and the Cognitive Sciences 7: 85-97.

- Strawson, P.F. 1962. 'Freedom and Resentment.' In his Freedom and Resentment and Other Essays. Oxford and New York: Oxford University Press, 2008.

- Tenenbaum, S. 2009. 'Knowing the Good and Knowing What One is Doing.' Canadian Journal of Philosophy 39 (supplement): 91-117.

- Velleman, D. 1992. 'The Guise of the Good.' Noûs 26: 3-26.

- Yasenchuk, K. 'Moral Realism and the Burden of Argument.' Southern Journal of Philosophy 35: 247-264.

\footnotetext{
${ }^{1}$ Personally, I find quite compelling Husserl's notion that perceptual experience is distinctive in presenting its objects in the flesh ('in persona,' as he writes). Seeing the tree in my backyard is phenomenally dissimilar to thinking about the same tree, inter alia, insofar as it presents the tree 'in the flesh.' This appears to mean that while both the thinking and the seeing represents the tree, the seeing represent the tree as in some sense present here at now, whereas the thought does not (for more on how to unpack in-the-flesh, see Kriegel 2019).

2 I am assuming here that pain has a(n intentional) object. This used to be a daring assumption, but in recent philosophical discussions of pain and pleasure it has become orthodoxy. There is of course lively debate over what the distinctive objects of pain are, but on my view pain does not have distinctive objects. What is distinctive of pain is rather its attitudinal character.
} 
${ }^{3}$ Manela (2016) presents a pair of different distinctions between gratitude and appreciation, but he uses the term 'appreciation' to denote a different kind of mental state, what he calls 'propositional gratitude,' such as we would report with a the locution grateful that. I have no doubt that the mental state Manela is interested in is a legitimate referent of 'appreciation' - more on this toward the end of this section. It is just a different mental state from the one I am interested in.

4 This kind of projective identification certainly appears to be much more pervasive for anger than for gratitude. The contingent causes of this asymmetry are something we can only speculate about. But the upshot is that anger about 'allocentric states of affairs,' so to speak, is in fact quite common. All the same, it is notable that this kind of identification is necessary for our ability to feel anger about matters that do not remotely concern us, whereas indignation does not require any such identification. That said, we should keep in mind that even in the absence of any identification there is substantial phenomenal overlap between anger and indignation, which makes labeling tricky more on that soon.

${ }^{5}$ Some second-personal approaches to morality treat resentment as a paradigmatically moral emotion, despite its lack of detachment from the subject's own involvement in the situation. But first, I think it is a limitation of these approaches that they cannot capture the "objective pretensions" of moral experience, and secondly, although resentment is often moral, it is unclear to me that it has to be moral. My corrupt referee seems to me to resent me because I got that grant at her expense. In getting this grant at her expense, I have harmed her, but I have not wronged her.

${ }^{6}$ It is interesting to think about what the distinctive attitudinal character of guilt might be. On the face of it, guilt represents-as-morally-blameworthy just as indignation does, but does so in a firstpersonal way whereas indignation is third-personal. One interesting question here is whether the first-personal/third-personal distinction belongs properly in the attitude or content of these emotions - which in turn may have interesting implications for the structure of the realm of moral experience.

7 Work for this paper was supported by the French National Research Agency's grant ANR-17EURE-0017, as well as by grant 675415 of the European Union's Horizon 2020 Research and Innovation program and a Bessel Research Award from Germany's Alexander von Humboldt's Foundation. For comments on a previous draft, I am grateful to Walter Sinnott-Armstrong, Charles Siewert, and two anonymous referees for ETMP. I have also benefited from discussions in a semester-long seminar on the moral emotions at Rice University; I am grateful to the seminar participants, Mustafa Aghahosseini, Christian Blacèt, Anna Gisutina, Hitkarsh Kumar, Daniel Pinto, Reuben Sass, and Patricia Thornton. 